\title{
E-mail communication practices and preferences among patients and providers in a large comprehensive cancer center
}

DOI:

10.1200/JOP.2015.008722

\section{Document Version}

Final published version

Link to publication record in Manchester Research Explorer

Citation for published version (APA):

Cook, N., Maganti, M., Dobriyal, A., Sheinis, M., Wei, A. C., Ringash, J., \& Krzyzanowska, M. K. (2016). E-mail communication practices and preferences among patients and providers in a large comprehensive cancer center. Journal of Oncology Practice, 12(7), 676-684. https://doi.org/10.1200/JOP.2015.008722

\section{Published in:}

Journal of Oncology Practice

\section{Citing this paper}

Please note that where the full-text provided on Manchester Research Explorer is the Author Accepted Manuscript or Proof version this may differ from the final Published version. If citing, it is advised that you check and use the publisher's definitive version.

\section{General rights}

Copyright and moral rights for the publications made accessible in the Research Explorer are retained by the authors and/or other copyright owners and it is a condition of accessing publications that users recognise and abide by the legal requirements associated with these rights.

\section{Takedown policy}

If you believe that this document breaches copyright please refer to the University of Manchester's Takedown Procedures [http://man.ac.uk/04Y6Bo] or contact uml.scholarlycommunications@manchester.ac.uk providing relevant details, so we can investigate your claim.

\section{OPEN ACCESS}




\section{E-Mail Communication Practices and Preferences Among Patients and Providers in a Large Comprehensive Cancer Center}

Natalie Cook, MDBChB, PhD, Manjula Maganti, MSc, Aditi Dobriyal, Michal Sheinis, Alice C. Wei, MD, MSc, Jolie Ringash, MD, MSc, and Monika K. Krzyzanowska, MD, MPH

QUESTION ASKED: What are the current e-mail communication practices and preferences of patients and physicians in oncology?

University of Toronto; and Institute for Clinical Evaluative Sciences, Toronto, Ontario, Canada

Corresponding author: Monika K. Krzyzanowska, MD, MPH, Princess Margaret Cancer Centre, 610 University Ave, Suite 5-206, Toronto, Ontario, Canada M5G 2M9; e-mail:monika.krzyzanowska@ uhn.ca.

Disclosures provided by the authors are available with this article at jop.ascopubs.org.

SUMMARY ANSWER: E-mail is commonly used by patients and physicians to communicate with each other and with other health care providers about patient-related issues. However, e-mail communication is infrequently documented in patient records.

WHAT WE DID: Separate cross-sectional surveys were administered to patients and physicians to ascertain current practices and preferences for e-mail communication by each group. A chart review was conducted to assess the impact of e-mail communication on care.

WHAT WE FOUND: Approximately $41 \%$ of patients reported previous contact with a member of their health care team. Eighty percent of physicians reported previous contact with a patient via e-mail. All physicians reported using e-mail regularly with other health care providers to manage care. Patient factors associated with higher likelihood of e-mail contact with the health care team included younger age, higher education, higher income, enrollment in a clinical trial, and receipt of multiple treatments. Physician factors associated with higher likelihood of e-mail contact with patients included older age, more senior clinical position, and higher patient volume. Both patients and physicians saw value in e-mail communication for certain clinical scenarios. In terms of concerns with using e-mail to communicate, patients' main concerns related to confidentiality and e-mail not being received whereas physicians were concerned about miscommunication and workload. E-mail correspondence was documented in only $9 \%$ of 962 charts reviewed.

BIAS, CONFOUNDING FACTOR(S), DRAWBACKS: This is a single-center study in a large comprehensive cancer center so it is unknown whether these results would be applicable to smaller centers. The response rate to the physicians survey was low. Finally, due to the low frequency of documented e-mail communications, we were unable to evaluate the impact on patient care.

REAL-LIFE IMPLICATIONS: Patients and physicians are commonly using e-mail to communicate about health care matters and this use can be further developed with appropriate guidance. The use of patient portals with direct links to e-mail communication are likely to change this field significantly. There may also be concerns about widening the health care gap for certain groups of patients, so care must be taken to avoid this. JOP 
Princess Margaret Cancer Centre: University of Toronto; and Institute for Clinical Evaluative Sciences, Toronto, Ontario, Canada

\section{ASSOCIATED CONTENT}

Appendix DOl: 10.1200/JOP.2015 008722 jop.ascopubs.org on June 28, 2016.

\title{
E-Mail Communication Practices and Preferences Among Patients and Providers in a Large Comprehensive Cancer Center
}

\author{
Natalie Cook, MDBChB, PhD, Manjula Maganti, MSc, Aditi Dobriyal, Michal Sheinis, \\ Alice C. Wei, MD, MSc, Jolie Ringash, MD, MSc, and Monika K. Krzyzanowska, MD, MPH
}

\section{Abstract}

\section{Purpose}

Little is known about how electronic mail (e-mail) is currently used in oncology practice to facilitate patient care. The objective of our study was to understand the current e-mail practices and preferences of patients and physicians in a large comprehensive cancer center.

\section{Methods}

Separate cross-sectional surveys were administered to patients and physicians (staff physicians and clinical fellows) at the Princess Margaret Cancer Centre. Logistic regression was used to identify factors associated with current e-mail use. Record review was performed to assess the impact of e-mail communication on care.

\section{Results}

The survey was completed by 833 patients. E-mail contact with a member of the health care team was reported by $41 \%$ of respondents. The team members contacted included administrative assistants (52\%), nurses (45\%), specialist physicians (36\%), and family physicians (18\%). Patient factors associated with a higher likelihood of e-mail contact with the health care team included younger age, higher education, higher income, enrollment in a clinical trial, and receipt of multiple treatments. Eighty percent of physicians ( $n=63$ of 79 ) reported previous contact with a patient via e-mail. Physician factors associated with a greater likelihood of e-mail contact with patients included older age, more senior clinical position, and higher patient volume. Nine hundred sixty-two patient records were reviewed, with e-mail correspondence documented in only $9 \%$ of cases.

\section{Conclusion}

E-mail is commonly used for patient care but is poorly documented. The use of e-mail in this setting can be developed with appropriate guidance; however, there may be concerns about widening the gap between certain groups of patients.

\section{INTRODUCTION}

Electronic devices and electronic communication are being used by patients and physicians on a daily basis. In North America, approximately $88 \%$ of the population has an Internet connection today compared with only $1 \%$ in $1995,{ }^{1}$ and the average number of electronic mail (e-mail) accounts per person is estimated to be $1.5 .^{2}$ Not surprisingly, e-mail has emerged as an important communication method. 
With the increase in Internet and e-mail use, there has been a corresponding rise in the amount of medical information online, the so-called E-health. Although there have been some publications in the area of E-health, there remains a paucity of research on the use and impact of e-mail communication specifically among health care professionals and patients. ${ }^{3-6}$ A recent Cochrane review on the effects of e-mail for communication between health care professionals identified only one trial, providing insufficient evidence for guiding clinical practice regarding the use of e-mail between health care professionals. ${ }^{7}$

E-mail advantages include convenience and low cost. The written nature of the e-mail can be of value as a reference for the patient. It potentially allows easier access to a physician and could reduce unnecessary follow-ups for simple questions. However, there are also disadvantages to e-mail communication, including concerns about privacy and security, the timeliness of response, and a lack of clarity of communication. ${ }^{3,8,9}$ Physicians may also be concerned about the potential for e-mail to increase workload.

Guidelines for e-mail communication between patients and physicians exist but most were published some time ago. ${ }^{10-12}$ These guidelines recommend that physicians check applicable regulatory and statutory requirements and obtain explicit consent from patients for e-mail communication, and they comment on the risks involved. A more recent publication provides guidance on e-mail communication among health care providers, ${ }^{13}$ but awareness of and compliance with the guidelines among physicians are unknown.

The few studies that have examined patients' opinions regarding e-mail communication for health care issues in oncology practice found that patients like e-mail because of its convenience, efficiency, and timeliness. However, the number of patients studied was small and the number of disease sites was limited, and there were no direct questions about e-mailing health care providers. ${ }^{14-16}$ There have been studies investigating Internet use for health care in oncology practice, some of which included questions about e-mail, but none directly assessed physician and patient e-mail interactions. ${ }^{17,18}$ To date, no studies have evaluated physicians' opinions on communicating with patients or about patients via e-mail in oncology practice. Furthermore, we do not currently understand the impact of e-mail communication on clinical care. The goals of this study were to understand current patterns of e-mail communication between oncology patients and their physicians, to gather patients' and physicians' perspectives on this form of communication, and to evaluate the documentation of such communication in the medical record.

\section{METHODS}

\section{Study Overview and Setting}

We performed anonymous, cross-sectional surveys of patients and physicians at the Princess Margaret Cancer Centre (PMC), the largest comprehensive cancer center in Canada with approximately 12,000 new patients seen each year. ${ }^{19}$ At the time of the study, there were 100 active staff physicians and fellows in the Department of Medical Oncology and Hematology, 104 in the Department of Surgical Oncology, and 69 in the Department of Radiation Oncology. At the time of the surveys, our institution did not routinely collect patients' e-mail addresses, provide patients with e-mail contact for providers, or have a patient portal, and patients did not have routine access to their medical records. The study was approved by the University Health Network research ethics board.

\section{Questionnaire Development and Recruitment}

\section{Patient Survey}

The patient survey consisted of 18 multipart questions that assessed five domains: (1) demographics, (2) digital literacy skills, (3) use of the Internet for health-related needs, (4) use of e-mail for communication with health care team (HCTs), and (5) preferences for and barriers to electronic communication for facilitating cancer care. The survey was developed in an iterative fashion by the study team and was pilot tested with 10 hospital volunteers from our institution. Adult patients attending ambulatory clinics at the PMC were recruited to complete the paper survey during a 6-week period (March 3 to April 11, 2014). New patients, as well as those receiving active treatment or under surveillance, were eligible. To obtain a representative sample of patients, recruitment rotated in a variety of clinics. It was not possible to calculate a formal response rate for the patient survey because it was not feasible to track all patients who were approached.

\section{Physician Survey}

The physician survey had 22 multipart questions that assessed five domains: (1) demographics, (2) use of e-mail for communicating with patients, (3) use of e-mail for reporting patient results, (4) use of e-mail for communicating with other health professionals, and (5) preferences for and barriers to electronic 
communication in hospital practice. The survey was pilot tested with 10 clinical fellows and staff physicians from our institution. All staff physicians and fellows in medical, radiation, and surgical oncology at the PMC were invited by e-mail to participate in the survey using the electronic Web-based platform Fluid Survey. Follow-up requests were sent by e-mail at 2 weeks, and then 2 days before the survey deadline.

\section{Record Abstraction}

To understand the impact of e-mail communication on clinical care, a random record review of patient records was performed to characterize if and how e-mail communication is documented in the electronic patient record. We included patients who were assessed in one of the ambulatory clinics at the PMC at least once within the recruitment period. Patients were identified using clinic lists available from our institution's scheduling software. Data from the electronic patient records were abstracted using a standardized form specifically developed for the study. Documentation of e-mail communication for up to a year before the date of assessment was evaluated. We recorded how often e-mail communication was documented, the timing of the documentation, the e-mail content, the involved parties, and the potential impact on clinical care.

\section{Statistical Analysis}

Data on categorical variables were reported as frequencies and percentages. Any partially completed questionnaires were included, but only questions that were answered were included in the analysis; hence, the denominators varied by question. Logistic regression was used to evaluate the factors associated with e-mailing the HCT in the patient survey, with corresponding odds ratios, $95 \% \mathrm{CIs}$, and $P$ values reported. Factors considered in this analysis included demographic variables such as age, education, income, and Internet literacy, as well as clinical variables such as cancer site, clinical trial participation, and types of treatments received. Variables significant in univariate analysis were entered into the multivariable model. Logistic regression was also used to evaluate the factors associated with e-mail contact with patients in the physician survey, but because of the small sample size, only univariate analysis was undertaken. Factors considered in the analysis of the physician surveys included age, sex, specialty, position, patient volume, and awareness of e-mail guidelines. Statistical significance was set at a $P$ value $\leq .05$ (two-sided). SAS Version 9.3 (SAS Institute, Cary, NC) was used for all analyses.

\section{RESULTS}

\section{Patient Survey}

The survey was completed by 833 patients, with a wide variety of cancer diagnoses and treatments. Most patients completing the survey spoke English (85\%). The majority of patients had access to the Internet (90\%) and an e-mail account (88\%) at home and used both on a daily basis (Table 1 ).

Forty-one percent of patients reported previous e-mail contact with a member of their HCT. Among 338 patients who provided information on the type of provider they had been in contact with, administrative assistants were the most common team members contacted (52\%), followed by specialist physicians (36\%), clinic nurses (29\%), and clinical trials nurses (17\%). A further $18 \%$ had e-mailed primary care practitioners, and $3 \%$ had e-mailed with both specialists and primary care physicians. Other providers who had been contacted included pharmacists $(4 \%)$, social workers $(<1 \%)$, and research coordinators $(<1 \%)$. Of the patients who had previous e-mail contact with the HCT, 39\% had e-mailed multiple members of their HCT; however, the majority of patients would only e-mail once a month or less (66\%). Of the patients who had used e-mail with any provider, $87 \%$ were either satisfied or very satisfied with this communication method.

Younger patients, patients with a higher education, patients with a higher income, and patients who had participated in a clinical trial or who had received multiple treatment modalities had a greater likelihood of e-mail contact with the HCT in the univariate analysis (Table 2). There was also variation depending on tumor type. Multivariable results were similar to the univariate analysis (Table 2).

Patients with prior e-mail contact with their HCT had fewer concerns about using e-mail in the future compared with the group that did not have prior e-mail contact (60\% $v 70 \%$, $P=.003)$. The main concerns were confidentiality (38\%) and the possibility that the e-mail may not be received (41\%). Thirty-five percent of all responders had no concerns. Eighty percent of patients who had e-mailed providers previously expressed future interest in e-mailing, compared with only $47 \%$ of patients who did not have previous e-mail contact with their HCT $(P<.001)$.

\section{Physician Survey}

The physician survey was completed by 80 of 273 physicians contacted (response rate, 29\%, Table 1). Forty-six percent of responders were under the age of 40 years. The majority of 
responders were from medical and surgical oncology specialties. Eighty percent of physicians reported previous contact with a patient via e-mail; however, only $56 \%$ of these physicians had ever read e-mail communication guidelines. When a physician had been in contact with a patient via e-mail, it was usually the patient who had made the first contact (67\%), and the contact was infrequent (monthly [29\%] or rarely [37\%]). When asked whether patients should have the option to contact physicians via e-mail, $16 \%$ felt this should never be an option; 62\%, rarely or sometimes an option; and $22 \%$, always or frequently an option. When they had used e-mail as a form of communication with a patient, $42 \%$ of physicians were either satisfied or very satisfied with this form of communication, and $13 \%$ were not satisfied.

In the univariate analysis, staff physicians, older physicians, those who had graduated from medical school $>10$ years previously, and those who saw more patients had an increased likelihood of e-mail contact with patients (Table 3). Multivariate analysis was not performed because of the sample size. Forty-five percent of physicians thought patients should have to sign a consent to be able to use e-mail communication with their physician. When asked whether it would be appropriate for a patient to contact another member of their HCT via e-mail, $77 \%$ responded yes, with secretary/administrative assistant, clinic nurse, and trials nurse as the team members they would recommend the patient contact most frequently. Sixty percent of physicians would definitely or possibly use e-mail communication as a way of corresponding with patients in the future, with $35 \%$ not sure or unlikely; only $5 \%$ replied that they would never use e-mail communication with patients.

All responders had been in contact with other physicians about patients, and the majority had patient results sent to them via e-mail (78\%). The majority of physicians had been in e-mail contact with other physicians within the same health network. This happened frequently; $60 \%$ responded to e-mail messages about patients on a daily basis. When contacting physicians from outside their network, but within the same province, $68 \%$ e-mailed between weekly and monthly about patients.

Physicians' concerns about e-mail included miscommunication (83\%), legal issues (80\%), patients seeking urgent medical advice $(72 \%)$, increase in workload $(60 \%)$, patient confidentiality (65\%), and timeliness of response to e-mail (67\%). When asked about the benefits of using e-mail communication with patients, convenience $(65 \%)$, easy
Table 1. Demographics and Use of Internet and E-Mail in Patient and Physician Survey Populations

Variable

No. (\%)

\begin{tabular}{|c|c|}
\hline \multicolumn{2}{|l|}{$\begin{array}{l}\text { Patient survey (total number of } \\
\text { respondents } n=833[100 \%])^{*}\end{array}$} \\
\hline \multicolumn{2}{|l|}{ Age, years } \\
\hline $18-35$ & $78(9)$ \\
\hline $36-50$ & $166(20)$ \\
\hline $51-65$ & $312(38)$ \\
\hline $66-80$ & $239(29)$ \\
\hline$>80$ & $35(4)$ \\
\hline \multicolumn{2}{|l|}{ Sex } \\
\hline Female & $432(52)$ \\
\hline \multicolumn{2}{|l|}{ Cancer type } \\
\hline Breast & $89(11)$ \\
\hline $\mathrm{Gl}$ & $186(22)$ \\
\hline Genitourinary & $140(17)$ \\
\hline Gynecologic & $78(9)$ \\
\hline Hematologic & $138(17)$ \\
\hline No cancer diagnosis/other† & $112(14)$ \\
\hline Skin, sarcoma, lung & $89(11)$ \\
\hline \multicolumn{2}{|l|}{ Surgery for cancer } \\
\hline No surgery & $401(50)$ \\
\hline Surgery + other & $307(38)$ \\
\hline Surgery only & $102(13)$ \\
\hline \multicolumn{2}{|l|}{ Previous/current chemotherapy } \\
\hline Chemotherapy only & $81(10)$ \\
\hline Chemotherapy + other & $329(41)$ \\
\hline No chemotherapy & 401 (49) \\
\hline \multicolumn{2}{|l|}{ Previous/current radiotherapy } \\
\hline No radiotherapy & $554(68)$ \\
\hline Radiotherapy only & $24(3)$ \\
\hline Radiotherapy + other & $233(29)$ \\
\hline \multicolumn{2}{|l|}{ Previous/current clinical trial } \\
\hline Yes & $118(15)$ \\
\hline \multicolumn{2}{|l|}{ Time at Princess Margaret Cancer } \\
\hline \multicolumn{2}{|l|}{ Centre, years } \\
\hline$<1$ & $363(44)$ \\
\hline $1-2$ & $148(18)$ \\
\hline $2-5$ & $184(23)$ \\
\hline$>5$ & $123(15)$ \\
\hline \multicolumn{2}{|l|}{ Income, \$ } \\
\hline$<20,000$ & $84(10)$ \\
\hline $20,000-39,999$ & $113(14)$ \\
\hline $40,000-69,999$ & $145(18)$ \\
\hline$>70,000$ & $268(33)$ \\
\hline Prefer not to answer & $201(25)$ \\
\hline \multicolumn{2}{|l|}{ Education } \\
\hline Grade school & $48(6)$ \\
\hline High school & $157(19)$ \\
\hline Technical school & $130(16)$ \\
\hline University & $258(32)$ \\
\hline Professional/graduate degree & $221(27)$ \\
\hline
\end{tabular}


Table 1. Demographics and Use of Internet and E-Mail in Patient and Physician Survey Populations (continued)

\begin{tabular}{|c|c|}
\hline Variable & No. $(\%)$ \\
\hline \multicolumn{2}{|l|}{ Internet at home } \\
\hline Yes & $728(90)$ \\
\hline \multicolumn{2}{|l|}{ Frequency of Internet use } \\
\hline A few times a month & $13(2)$ \\
\hline A few times a week & $96(12)$ \\
\hline Every day & $655(81)$ \\
\hline Less than once a month & $31(4)$ \\
\hline Once a month & $2(<1)$ \\
\hline Once a week & $15(2)$ \\
\hline \multicolumn{2}{|c|}{ Search Internet for health reasons } \\
\hline Yes & $618(76)$ \\
\hline \multicolumn{2}{|l|}{ E-mail account } \\
\hline Yes & $711(88)$ \\
\hline \multicolumn{2}{|l|}{ Number of accounts } \\
\hline Multiple & 395 (49) \\
\hline One & $417(51)$ \\
\hline \multicolumn{2}{|l|}{ Frequency of e-mail use } \\
\hline A few times a month & $24(3)$ \\
\hline A few times a week & $111(14)$ \\
\hline Every day & $627(77)$ \\
\hline Less than once a month & $19(2)$ \\
\hline Once a month & $8(1)$ \\
\hline Once a week & $22(3)$ \\
\hline \multicolumn{2}{|c|}{$\begin{array}{l}\text { Physician survey (total number of } \\
\text { respondents } n=80[100 \%])^{*}\end{array}$} \\
\hline \multicolumn{2}{|c|}{ Age, years } \\
\hline$<40$ & $36(46)$ \\
\hline $41-60$ & $32(41)$ \\
\hline$>61$ & $10(13)$ \\
\hline \multicolumn{2}{|l|}{ Sex } \\
\hline Female & $38(48)$ \\
\hline Male & $41(52)$ \\
\hline \multicolumn{2}{|l|}{ Specialty } \\
\hline Medical oncology & $32(41)$ \\
\hline Radiation oncology & $15(19)$ \\
\hline Hematology & $11(14)$ \\
\hline Surgical oncology & $21(27)$ \\
\hline \multicolumn{2}{|l|}{ Position } \\
\hline Staff & $49(62)$ \\
\hline Fellow & $30(38)$ \\
\hline \multicolumn{2}{|l|}{ Job description } \\
\hline Clinical fellow & $30(38)$ \\
\hline Clinical investigator & $30(38)$ \\
\hline Clinician scientist & $10(12)$ \\
\hline Clinical teacher & $8(10)$ \\
\hline Other & $2(2)$ \\
\hline \multicolumn{2}{|l|}{$\begin{array}{l}\text { Years since graduation from } \\
\text { medical school }\end{array}$} \\
\hline$<10$ & $19(24)$ \\
\hline $10-20$ & $36(46)$ \\
\hline$>20$ & $24(30)$ \\
\hline (continu & \\
\hline
\end{tabular}

Table 1. Demographics and Use of Internet and E-Mail in Patient and Physician Survey Populations (continued)

\begin{tabular}{|c|c|}
\hline Variable & No. $(\%)$ \\
\hline \multicolumn{2}{|c|}{$\begin{array}{l}\text { Number of patients seen in clinic } \\
\text { per week }\end{array}$} \\
\hline$<30$ & 39 (49) \\
\hline$>30$ & $40(51)$ \\
\hline \multicolumn{2}{|c|}{$\begin{array}{l}\text { Have you read guidelines about e-mail } \\
\text { communication? }\end{array}$} \\
\hline No & $38(48)$ \\
\hline Yes & $42(52)$ \\
\hline \multicolumn{2}{|c|}{$\begin{array}{l}\text { Have you ever been in contact with a } \\
\text { patient via e-mail? }\end{array}$} \\
\hline No & $16(20)$ \\
\hline Yes & $63(80)$ \\
\hline \multicolumn{2}{|c|}{$\begin{array}{l}\text { Have you ever contacted/been } \\
\text { contacted by another physician } \\
\text { about a patient via e-mail? }\end{array}$} \\
\hline No & $0(0)$ \\
\hline Yes & $78(100)$ \\
\hline \multicolumn{2}{|c|}{$\begin{array}{l}\text { Have you ever had a patient's results } \\
\text { sent to you via e-mail? }\end{array}$} \\
\hline No & $17(22)$ \\
\hline Yes & $60(78)$ \\
\hline
\end{tabular}

*The total number of respondents for both the patient and physician survey varied for each question. This is the maximal number of respondents who answered at least one question on each survey.

tIncludes patients being seen as new patients, patients under investigation with no diagnosis as yet, and patients diagnosed with preinvasive or benign disease.

access to physicians (60\%), and improved communication with patients (53\%) were reported frequently. Other potential benefits included reduced clinic follow-up (45\%) and cost effectiveness (43\%).

Patients and physicians were asked to rank their preference for different means of communication (e-mail, online, telephone, and in person) for different scenarios. Among patients, e-mail was the preferred option for managing blood test results (69\%) and appointments (73\%) and when asking for travel directions (76\%). The majority of patients indicated they would not use e-mail for urgent medical care $(66 \%)$ or for biopsy results (53\%). The two scenarios for which physicians preferred e-mail were for arranging appointments (64\% answering always or frequently) and for travel directions ( $46 \%$ answering always or frequently). They did not think e-mail communication should be used for urgent medical advice (60\% responding never) or biopsy or radiology results (60\% responding never or rarely) or to give medical advice to a patient they had not met (79\% answering never). 
Table 2. Factors Associated With E-Mailing Health Care Team Members in the Patient Survey

\begin{tabular}{|c|c|c|c|c|c|c|}
\hline \multirow[b]{2}{*}{ Variable } & \multicolumn{3}{|c|}{ Univariable Analysis } & \multicolumn{3}{|c|}{ Multivariable Analysis* } \\
\hline & Odds Ratio & $95 \% \mathrm{Cl}$ & $P$ & Odds Ratio & $95 \% \mathrm{Cl}$ & $P$ \\
\hline \multicolumn{7}{|l|}{ Age, years } \\
\hline $36-50$ & 2.4 & $1.6-3.6$ & $<.001$ & 2.0 & $1.2-2.9$ & .005 \\
\hline $51-65$ & 1.8 & $1.3-2.5$ & .0008 & 1.5 & $0.99-2.1$ & .056 \\
\hline $66-80$ & Referent & - & - & - & - & - \\
\hline Grade school & Referent & - & - & - & - & - \\
\hline High/technical & 4.5 & $1.7-11.7$ & .002 & 2.9 & $1.1-8.2$ & .037 \\
\hline Professional† & 7.7 & 3.0-19.9 & $<.001$ & 4.6 & $1.7-2.6$ & .003 \\
\hline \multicolumn{7}{|l|}{ Income, \$ } \\
\hline$<20,000$ & Referent & - & - & - & - & - \\
\hline Prefer not to answer & 1.02 & $0.58-1.8$ & .941 & 0.96 & $0.52-1.8$ & .89 \\
\hline \multicolumn{7}{|l|}{ Cancer site } \\
\hline Gynecology & Referent & - & - & - & - & - \\
\hline Breast & 1.9 & $1.03-3.8$ & .037 & 2.1 & $1.02-4.3$ & .04 \\
\hline $\mathrm{Gl}$ & 1.8 & $1.01-3.2$ & .045 & 2.5 & $1.3-4.8$ & .005 \\
\hline Genitourinary & 1.8 & $1.01-3.4$ & .045 & 2.5 & $1.3-4.9$ & .008 \\
\hline Hematology & 2.3 & $1.3-4.2$ & .006 & 3.0 & $1.5-5.8$ & .002 \\
\hline SSL & 1.7 & $0.83-3.4$ & .153 & 1.7 & $0.82-3.5$ & .15 \\
\hline Other $\ddagger$ & 1.4 & $0.62-3.1$ & .422 & 2.5 & $0.96-6.5$ & .06 \\
\hline No cancer $\ddagger$ & 1.6 & $0.83-3.1$ & .158 & 3.1 & $1.3-6.9$ & .008 \\
\hline Chemotherapy & & & & Not Applicable & & \\
\hline Yes & 1.5 & $1.1-1.9$ & .005 & & & \\
\hline No & Referent & - & - & & & \\
\hline Previous surgery & & & & Not Applicable & & \\
\hline Yes & 1.2 & $0.94-1.7$ & .12 & & & \\
\hline No & Referent & - & - & & & \\
\hline Radiotherapy & & & & Not Applicable & & \\
\hline Yes & 1.01 & $0.75-1.4$ & .95 & & & \\
\hline No & Referent & - & - & & & \\
\hline Hormone treatment & & & & Not Applicable & & \\
\hline Yes & 0.87 & $0.28-2.7$ & .81 & & & \\
\hline No & Referent & - & - & & & \\
\hline Stem cell transplant & & & & Not Applicable & & \\
\hline Yes & 1.73 & $0.84-3.6$ & .13 & & & \\
\hline No & Referent & - & - & & & \\
\hline & (con & d on follow & ge) & & & \\
\hline
\end{tabular}


Table 2. Factors Associated With E-Mailing Health Care Team Members in the Patient Survey (continued)

\begin{tabular}{|c|c|c|c|c|c|c|}
\hline Variable & \multicolumn{3}{|c|}{ Univariable Analysis } & \multicolumn{3}{|c|}{ Multivariable Analysis* } \\
\hline Yes & 22.7 & $7.1-72.6$ & $<.001$ & & & \\
\hline No & Referent & - & - & & & \\
\hline No & Referent & - & - & & & \\
\hline Searched for health information on Internet & & & & & Not applicable* & \\
\hline Yes & 6.2 & 4.0-9.6 & $<.001$ & & & \\
\hline No & Referent & - & - & & & \\
\hline
\end{tabular}

NOTE. Number of patients used in the multivariable analysis = 777: 329 e-mailed health care team members and 448 did not e-mail health care team members; 56 had missing data.

Abbreviations: SSL, skin, sarcoma and lung cancers.

* Some of the variables significant in the univariable analysis were not included in the multivariable model because of correlation; specifically, demographics and Internet habits were correlated. Therefore, for the multivariable analysis, the model with the best performance as measured by the area under the curve (AUC) is presented (AUC of 0.71 compared with 0.68 , where Internet habits, rather than demographics, are considered).

tIncludes university or professional/graduate degree.

¥Includes patients being seen as new patients, patients under investigation with no diagnosis as yet, and patients diagnosed with preinvasive or benign disease.

A comparison of the physician and patient survey results (Appendix Fig A1, online only) revealed a similar pattern concerning preferences for use of e-mail in the described scenarios, although physicians tended to favor e-mail for scenarios that may not directly involve them.

When asked about the fate of the e-mail messages about patients sent from other providers, and from patients directly, the majority of responders reported keeping the e-mail in their in-box without transcribing any information to the patients' electronic record (Appendix Fig A1). The second most frequent fate was deleting the e-mail once actioned.

\section{Record Review Results}

E-mail correspondence was documented in 87 of 962 records (9\%) that were reviewed. In 77 cases (8\%), the e-mail was found in the scanned documents folder, and in 10 cases (1\%), it was found as a dictated physician note. Most commonly (38 of 87 cases [44\%]), the e-mail was a record of a physician-tophysician communication about patient results or appointment changes. There were also e-mail messages from administrative assistants, nurses, and referrals/bookings coordinators, all sent to physicians and scanned. There were only six recorded patient-to-physician e-mail communications. Three of these were regarding patient appointments and three were to update the patient about blood results.

\section{DISCUSSION}

To the best of our knowledge, this is the largest study to date to define the current use of and future preferences for e-mail communication among patients and physicians in oncology practice. Patients who had previously e-mailed their HCT were younger and had a higher income and higher education compared with those who had not e-mailed, similar to the results of previous studies evaluating Internet use in oncology practice. ${ }^{16,18}$ Patients were interested in using e-mail to manage blood test results, to book appointments, and to ask for travel directions. Among physicians, older age and higher patient volume were significantly associated with an increased likelihood of e-mail contact with patients. Physicians thought e-mail should be used for arranging medical appointments and providing travel directions, scenarios that most likely would not involve them directly. In general, patients tended to favor e-mail use more than physicians did for the majority of the scenarios described.

A recent study found that patients advocated Internetbased technology in oncology practice. ${ }^{20}$ In this study, concerns were raised about the differences in perceived ease of use in relation to age and socioeconomic status, factors also found to be an issue in our study. Interventions to increase access to computers and to improve computer literacy and e-mail use may be helpful for certain groups of patients; however, whether this would improve communication between patients 
Table 3. Factors Associated With E-Mailing in the Physician Survey

\begin{tabular}{|c|c|c|c|}
\hline \multirow[b]{2}{*}{ Variable } & \multicolumn{3}{|c|}{ Univariable Analysis } \\
\hline & Odds Ratio & $95 \% \mathrm{Cl}$ & $P$ \\
\hline \multicolumn{4}{|l|}{ Age, years } \\
\hline$\leq 40$ & Referent & - & - \\
\hline$>40$ & 12.7 & $2.6-61.2$ & .0015 \\
\hline Sex & & & .82 \\
\hline Male & 1.1 & $0.38-3.4$ & \\
\hline Female & Referent & - & \\
\hline Position & & & $<.001$ \\
\hline Staff & 20.4 & 4.1-100.7 & \\
\hline Fellow & Referent & - & \\
\hline \multicolumn{4}{|l|}{ Specialty } \\
\hline Medical oncology & 0.57 & $0.10-3.2$ & .52 \\
\hline Radiation oncology & 2.9 & $0.23-36.9$ & .41 \\
\hline Surgical oncology & 0.94 & $0.14-6.2$ & .95 \\
\hline Hematology & Referent & - & \\
\hline \multicolumn{4}{|l|}{$\begin{array}{l}\text { Years since graduation } \\
\text { from medical school }\end{array}$} \\
\hline$<10$ & Referent & - & \\
\hline $10-20$ & 4 & $1.1-14.3$ & .03 \\
\hline$>20$ & 8.8 & $1.6-49.1$ & .13 \\
\hline \multicolumn{4}{|c|}{$\begin{array}{l}\text { Number of patients seen } \\
\text { in clinic each week }\end{array}$} \\
\hline$<30$ & Referent & - & - \\
\hline$>30$ & 4.2 & $1.2-14.3$ & .02 \\
\hline \multicolumn{4}{|l|}{$\begin{array}{l}\text { Previously read e-mail } \\
\text { guidelines }\end{array}$} \\
\hline Yes & 2.08 & $0.67-6.4$ & .20 \\
\hline No & Referent & - & - \\
\hline
\end{tabular}

and providers remains to be determined. There will always be patients who do not want to use the Internet or e-mail, and this must be taken into consideration with advancing technology. Randomized studies should be performed to assess the impact of new electronic technologies and patient portals in different groups of patients to determine their impact on care.

Interestingly, older physicians in our study were more likely to report previous contact with patients via e-mail. This may be because older physicians have likely seen a greater volume of patients, especially in a longitudinal fashion; hence, they may have had a greater opportunity for contact. Secondly, our institution does not routinely hand out physician e-mail contact, and it may be easier to find e-mail addresses for more senior and established physicians through search engines such as Google.
Despite the high frequency of self-reported e-mail communication by physicians for patient care, e-mail communication was documented in only $9 \%$ of almost 1,000 patient records that were reviewed, suggesting poor documentation of e-mail communication. The majority of physicians reported keeping patient-related e-mail messages in their inbox but not transcribing the information to the patients' electronic record. Clear guidelines for documentation of e-mail communication and better integration between e-mail systems and the medical record are potential mechanisms for closing this gap. Use of patient portals for communication may also address the gap, although it may not facilitate documentation of communication between providers. ${ }^{21}$

Given the low frequency of documented e-mail communication in our audit, we were unable to evaluate its impact on clinical care. Review of physician e-mail accounts may be a better approach to determining the impact of e-mail communication on care. However, the ethical and legal issues surrounding this make it impossible without identifying the patients involved and obtaining consent from all parties involved, which was not feasible. Novel reimbursement models that incentivize documentation of e-mail communication in the medical record, or integration of e-mail with the medical record, may help documentation.

Although recommendations for e-mail communication exist from various medical governing bodies, ${ }^{10,22,23}$ improved visibility of these policies is needed. We encourage physicians to become familiar with these guidelines. We recommend that, at a minimum, physicians who participate in this type of communication with patients obtain explicit consent for e-mail communication that includes a discussion of the risks associated with unsecure e-mail accounts and expectations regarding the type of issues e-mail is appropriate for and when to expect a response.

There are limitations to our study. It was a single-center study set in a large academic comprehensive cancer center that included patients who were willing to participate and well enough to attend their outpatient appointments. With the patient survey, we were unable to assess the response rate because it was not feasible to track all patients who were approached, and it is possible that patients who declined participation in the survey were less likely to use e-mail. When approaching patients for the survey, the most common reasons for not participating were a language barrier (patient unable to speak English and attending clinic alone) or because the patient did not feel well enough, although we estimate this was the case 
for $<10 \%$ of the patients approached. The physician survey had a low response rate, so the true extent and impact of daily e-mail use by physicians for clinical care needs to be further defined because physicians are spending a significant proportion of their time dealing with patient-related issues via e-mail. ${ }^{24}$ The response rate could potentially have been increased by using other distribution methods, such as handing out paper surveys or using incentives. ${ }^{25}$ Last, we did not specifically ask why patients were contacting individual team members and therefore we cannot estimate what proportion of e-mail messages were for mundane reasons, such as appointment scheduling, versus medical advice.

In summary, e-mail is commonly used for patient care but is not well documented. The use of patient portals with a direct link to e-mail communication is likely to change this field significantly although not all vendors offer a direct link to e-mail communication. ${ }^{20,21,26}$ The use of e-mail in patientrelated health care with and without patient portals can be developed with appropriate guidance; however, because there may be concerns about widening the gap for certain groups of patients, care must be taken to avoid this. JoP

\section{Acknowledgment}

Presented at the ASCO Annual Meeting, Chicago, IL, June 2, 2015.

\section{Authors' Disclosures of Potential Conflicts of Interest}

Disclosures provided by the authors are available with this article at jop.ascopubs.org.

\section{Author Contributions \\ Conception and design: Natalie Cook, Jolie Ringash, \\ Monika K. Krzyzanowska \\ Financial support: Monika K. Krzyzanowska \\ Administrative support: Monika K. Krzyzanowska \\ Collection and assembly of data: Natalie Cook, Aditi Dobriyal, \\ Michal Sheinis}

Data analysis and interpretation: Natalie Cook, Manjula Maganti,

Alice C. Wei, Monika K. Krzyzanowska

Manuscript writing: All authors

Final approval of manuscript: All authors

Corresponding author: Monika K. Krzyzanowska, MD, MPH, Princess Margaret Cancer Centre, 610 University Ave, Suite 5-206, Toronto, Ontario, Canada M5G 2M9; e-mail:monika.krzyzanowska@uhn.ca.

\section{References}

1. Internet World Statistics. Useage and Population Statistics. Miniwatts Marketing Group 2015. www.internetworldstats.com

2. Radicati S. Email Statistics Report. The Radicati Group Website, The Radicati Group 2012. www.radicati.com
3. Delbanco T, Sands DZ: Electrons in flight-e-mail between doctors and patients. N Engl J Med 350:1705-1707, 2004

4. Pappas $\mathrm{Y}$, Atherton $\mathrm{H}$, Sawmynaden $\mathrm{P}$, et al: Email for clinical communication between healthcare professionals. Cochrane Database Syst Rev 9:CD007979, 2012

5. Atherton H, Sawmynaden P, Sheikh A, et al: Email for clinical communication between patients/caregivers and healthcare professionals. Cochrane Database Syst Rev 11:CD007978, 2012

6. Ye J, Rust G, Fry-Johnson Y, et al: E-mail in patient-provider communication: A systematic review. Patient Educ Couns 80:266-273, 2010

7. Goyder C, Atherton H, Car M, et al: Email for clinical communication between healthcare professionals. Cochrane Database Syst Rev 2:CD007979, 2015

8. Bitter J: E-mail in medical practice: Legal and ethical concerns. QRC Advis 16:1-8, 2000

9. Recupero PR, Rainey SE: Websites and E-mail in medical practice: Suggestions for risk management. Med Health R I 90:173-177, 2007

10. Kane B, Sands DZ: Guidelines for the clinical use of electronic mail with patients. The AMIA Internet Working Group, Task Force on Guidelines for the Use of ClinicPatient Electronic Mail. J Am Med Inform Assoc 5:104-111, 1998

11. Bovi AM, Council on Ethical and Judicial Affairs of the American Medical Association: Ethical guidelines for use of electronic mail between patients and physicians. Am J Bioeth 3:W-IF2, 2003

12. Pascal W, Tcheremenska-Greenhill A: E-mail guidelines. Can Fam Physician 52: 1539-1540, 2006

13. Malka ST, Kessler CS, Abraham J, et al: Professional e-mail communication among health care providers: Proposing evidence-based guidelines. Acad Med 90: 25-29, 2015

14. Dilts D, Ridner SH, Franco A, et al: Patients with cancer and e-mail: Implications for clinical communication. Support Care Cancer 17:1049-1056, 2009

15. Grimsbø GH, Finset A, Ruland CM: Left hanging in the air: Experiences of living with cancer as expressed through E-mail communications with oncology nurses. Cancer Nurs 34:107-116, 2011

16. Katzen C, Solan MJ, Dicker AP: E-mail and oncology: A survey of radiation oncology patients and their attitudes to a new generation of health communication. Prostate Cancer Prostatic Dis 8:189-193, 2005

17. Chen X, Siu LL: Impact of the media and the internet on oncology: Survey of cancer patients and oncologists in Canada. J Clin Oncol 19:4291-4297, 2001

18. Metz JM, Devine P. DeNittis A, et al: A multi-institutional study of Internet utilization by radiation oncology patients. Int J Radiat Oncol Biol Phys 56:1201-1205, 2003

19. Princess Margaret Cancer Centre. www.uhn.ca/PrincessMargaret

20. Girault A, Ferrua M, Lalloué B, et al: Internet-based technologies to improve cancer care coordination: Current use and attitudes among cancer patients. Eur J Cancer 51:551-557, 2015

21. Sarkar U, Bates DW: Care partners and online patient portals. JAMA 311 : 357-358, 2014

22. Using email communication with your patients: legal risks, The Canadian Medical Protection Association, 2009. www.cmpa-acpm.ca

23. Physician guidelines for online communication with patients Canadian Medical Association, 2005. www.cma.ca

24. Geynisman DM: E-mail anonymous: A physician's addiction. J Clin Oncol 33: 285-286, 2015

25. Martins $\mathrm{Y}$, Lederman RI, Lowenstein $\mathrm{CL}$, et al: Increasing response rates from physicians in oncology research: A structured literature review and data from a recent physician survey. Br J Cancer 106:1021-1026, 2012

26. Choudhry A, Hong J, Chong K, et al: Patients' preferences for biopsy result notification in an era of electronic messaging methods. JAMA Dermatol 151: 513-521, 2015 


\section{AUTHORS' DISCLOSURES OF POTENTIAL CONFLICTS OF INTEREST}

\section{E-Mail Communication Practices and Preferences Among Patients and Providers in a Large Comprehensive Cancer Center}

The following represents disclosure information provided by authors of this manuscript. All relationships are considered compensated. Relationships are self-held unless noted. I = Immediate Family Member, Inst = My Institution. Relationships may not relate to the subject matter of this manuscript. For more information about ASCO's conflict of interest policy, please refer to www.asco.org/rwc or jop.ascopubs.org/site/misc/ifc.xhtml.

\section{Natalie Cook}

No relationship to disclose

\section{Manjula Maganti}

No relationship to disclose

\section{Aditi Dobriyal}

No relationship to disclose

\section{Michal Sheinis}

No relationship to disclose

\section{Alice C. Wei}

Honoraria: Celgene

Consulting or Advisory Role: Histosonics, Sanofi Canada, Johnson \& Johnson

Speakers' Bureau: Celgene

\section{Jolie Ringash}

No relationship to disclose

Monika K. Krzyzanowska

Honoraria: Eisai, Bayer

Research Funding: AstraZeneca (Inst), Eisai (Inst), Exelixis (Inst), Novartis (Inst)

Other Relationship: Bayer/Onyx Pharmaceuticals 


\section{Appendix}

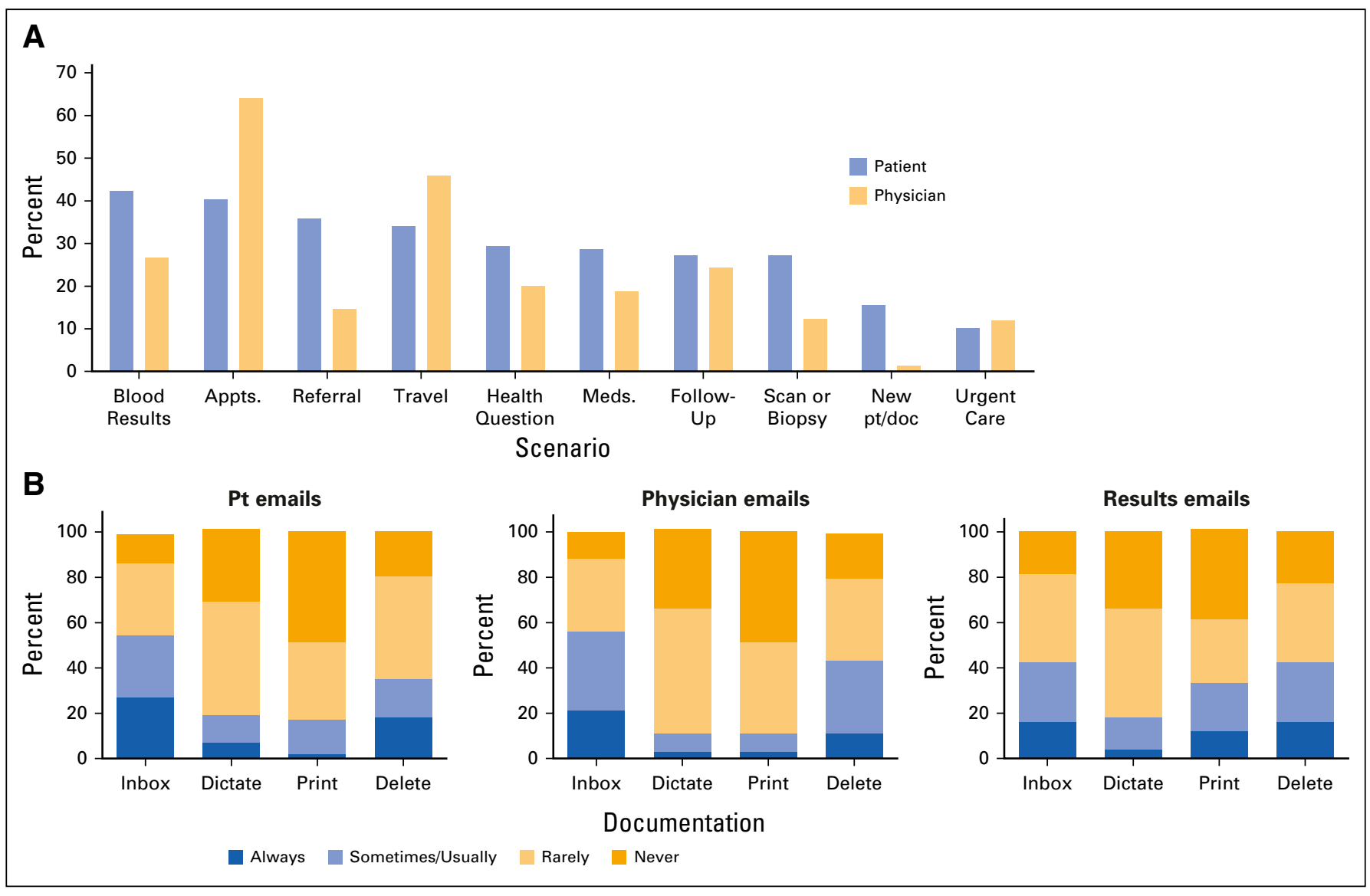

FIG A1. (A) Patient and physician opinions on e-mail communication used in different scenarios. In the patient survey, the first choice (best option) is illustrated. In the physician survey, the options "Always" and "Frequently" were combined and graphed. (B) Self-reported documentation of patient-related e-mail messages by physicians. Appts., appointments; doc, doctor; meds., medication advice; pt, patient. 